\title{
Seventh TEPHINET Global Scientific Conference in Amman, Jordan, November 2012
}

\author{
I. Iblan, ${ }^{7}$ B. Hajjawi, ${ }^{2}$ J. Mofleh, ${ }^{3}$ S. Abdelnour, ${ }^{3}$ Z.A. Memish ${ }^{4}$ and M. Al Nsour ${ }^{3}$
}

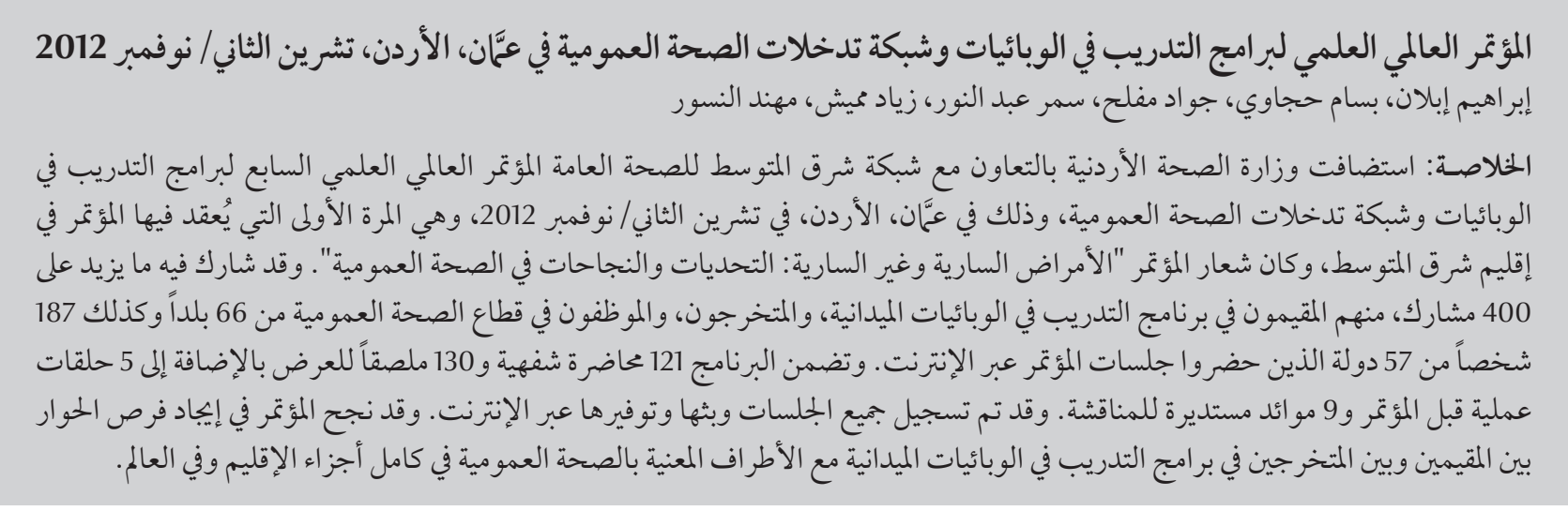

ABSTRACT The Jordanian Ministry of Health in collaboration with the Eastern Mediterranean Public Health Network (EMPHNET) hosted the Seventh Global Scientific Conference of the Training Programs in Epidemiology and Public Health Interventions Network (TEPHINET) in Jordan in November 2012. This was the first time this Conference was held in the Eastern Mediterranean region. The Conference theme was "communicable and noncommunicable diseases: public health challenges and successes". Over 400 participants including field epidemiology training program residents, graduates and public health officials from 66 countries attended the Conference as well as 187 people from 57 countries who attended the conference sessions on line. The programme included 121 oral and 130 poster presentations in addition to 5 pre-conference workshops and 9 roundtable discussions. All sessions were recorded and virtually broadcasted and made available on line. The Conference succeeded in creating opportunities for dialogue between residents and graduates of field epidemiology training programmes and public health stakeholders across the region and the globe.

\section{Septième conférence scientifique mondiale TEPHINET à Amman (Jordanie) en novembre 2012}

RÉSUMÉ Le ministère de la Santé jordanien, en collaboration avec le Réseau de la Méditerranée orientale pour la santé publique (EMPHNET) a accueilli la septième conférence scientifique mondiale TEPHINET - Training Programs in Epidemiology and Public Health Interventions Network [Réseau des programmes de formation à l'épidémiologie aux interventions de santé publique] qui s'est tenue en Jordanie en novembre 2012. C'est la première fois que la Région de Méditerranée orientale accueille cette conférence. Le thème était «maladies transmissibles et non transmissibles : difficultés et succès en santé publique ». Plus de 400 participants venant de 66 pays, dont des internes en épidémiologie de terrain, des médecins diplômés mais aussi des responsables de santé publique, y ont participé ; 187 personnes dans 57 pays ont suivi les sessions des conférences en ligne. Le programme comprenait 121 présentations orales et 130 sessions d'affiches, ainsi que cinq ateliers précédant la conférence et neuf tables rondes. Toutes les sessions ont été enregistrées, diffusées virtuellement et sont consultables en ligne. La conférence a permis de créer des opportunités de dialogue entre les internes et les médecins diplômés des cursus de formation en épidémiologie de terrain et les parties prenantes en santé publique dans la région et à l'échelle mondiale. 


\section{Introduction}

The Jordan Ministry of Health in collaboration with the Eastern Mediterranean Public Health Network (EMPHNET) hosted the Seventh Global Scientific Conference of the Training Programs in Epidemiology and Public Health Interventions Network (TEPHINET) in Amman, Jordan from 10 to $15 \mathrm{No-}$ vember, 2012. TEPHINET is a professional alliance of 57 Field Epidemiology Training Programs (FETPs) that are located in 86 countries [1]. The Eastern Mediterranean Public Health Network (EMPHNET) is a regional network linking field epidemiology and laboratory training programmes in the Eastern Mediterranean region [2]. FETP is a twoyear, applied epidemiology programme that helps countries to strengthen their public health system and infrastructure by training applied epidemiologists and leaders at the grass roots [3]. Core competencies of the FETPs are disease and outbreak detection, surveillance, response and translation of research findings into action [4], which are the same core capacities required for the implementation of International Health Regulation (IHR) (2005) [5].

Since 2000, TEPHINET has successfully conducted a biannual global conference in a different country and continent. This was the first time the conference was held in the Eastern Mediterranean region.

The Conference theme was "communicable and noncommunicable diseases: public health challenges and successes". Driven by the strong significance and diversity of this theme, a wide range of public health problems and concerns, both at the regional and global levels, were presented during the Conference.

\section{Setting the stage}

The Conference was convened under the patronage of Her Royal Highness
Princess Muna Al Hussein and was opened by His Excellency Dr Abdul Latif Wriekat, Minister of Health Jordan and Representative of Her Royal Highness. The Conference was also attended by: Dr Dionisio Herrera, Director, TEPHINET; Dr Peter Bloland, Director of Public Health Systems and Workforce Development Division, Centers for Diseases Control and Prevention (CDC), Atlanta; Dr Akram Eltom, World Health Organization (WHO) Representative, Jordan; Dr Ziad Memish, Deputy Minister for Public Health, Saudi Arabia and Chairperson of the Scientific Committee of the Conference; Dr Bassam Hajjawi, Director, General Primary Health Care, Ministry of Health, Jordan and Chairperson of the Organizing Committee of the Conference; and Dr Mohannad Al Nsour, Executive Director, EMPHNET.

\section{Highlights}

Over 400 participants including field epidemiology training program residents, graduates and public health officials from 66 countries attended the Conference. Likewise representatives from CDC, WHO's Regional Office for the Eastern Mediterranean and WHO Lyon office (International Health Regulations Coordination Department), international and national health organizations, and members of the academia attended the conference.

The Scientific Committee received 760 abstracts and each abstract was reviewed by 3 independent reviewers. Of the 760 abstracts submitted, 251 (from 51 countries) were recommended for oral and poster presentations; 121 oral and 130 poster presented in 36 oral and 4 poster sessions.

Of the presentations, $21 \%(\mathrm{n}=53)$ were on food-and waterborne diseases; $68 \%(36 / 53)$ of these 53 abstracts were from 9 countries: China, Malaysia, Pakistan, India, the Philippines, Brazil, Georgia, Kazakhstan, Lebanon and South Africa. Noncommunicable diseases were the focus of $15 \%(n=37)$ of the presentations and $77 \%(28 / 37)$ of these abstracts were from 10 countries: China, Tanzania, Indonesia, Iraq, Saudi Arabia, Jordan, Kenya, South Africa and Uganda. Vaccine-preventable diseases were the third most covered topic with $13 \%(n=33)$ of the abstracts and $85 \%(28 / 33)$ of these abstracts were from only 9 countries: Tanzania, Pakistan, Nigeria, China, Indonesia, Iraq, India, Thailand, Morocco and Ethiopia. Twelve percent of the abstracts were on respiratory diseases, $9 \%$ were on vector-borne diseases, $8 \%$ on HIV and sexually transmitted infections, $8 \%$ on zoonotic diseases, environmental and occupational health diseases comprised 5\% of all the abstracts, Maternal and child health comprised $4 \%$ and $5 \%$ of all the abstracts were under the other category (Table 1).

Five pre-conference workshops were conducted. The main objectives of these pre-conference workshops were to provide in-depth, skill and career building tools and provide opportunities for participants and FETP residents to advance their careers in future and to learn about important public health issues from international experts and leaders. The topics of these workshops were STOP polio, International Health Regulations (IHR) for epidemiologists, research ethics, One Health collaboration between government agencies and educational institutions in response to global emerging disease threats and building a voluntary corps of epidemiologists to increase global disease detection and verification. The workshops were conducted by $\mathrm{CDC}$, WHO and the Skoll Foundation. 


\begin{tabular}{|c|c|c|c|c|c|c|}
\hline \multirow[t]{2}{*}{ Topic } & \multicolumn{2}{|c|}{$\begin{array}{l}\text { Oral presentations } \\
\qquad(n=121)\end{array}$} & \multicolumn{2}{|c|}{$\begin{array}{l}\text { Poster presentations } \\
\qquad(n=130)\end{array}$} & \multicolumn{2}{|c|}{$\begin{array}{c}\text { Total } \\
(n=251)\end{array}$} \\
\hline & No. & $\%$ & No. & $\%$ & No. & $\%$ \\
\hline Food- and waterborne diseases & 23 & 19 & 30 & 23 & 53 & 21 \\
\hline Noncommunicable diseases & 20 & 17 & 17 & 13 & 37 & 15 \\
\hline Vaccine-preventable diseases & 19 & 16 & 14 & 11 & 33 & 13 \\
\hline Respiratory diseases & 12 & 10 & 17 & 13 & 29 & 12 \\
\hline Vector-borne diseases & 11 & 9 & 11 & 8 & 22 & 9 \\
\hline HIV and sexually transmitted infections & 11 & 9 & 10 & 8 & 21 & 8 \\
\hline Zoonotic diseases & 8 & 7 & 11 & 8 & 19 & 8 \\
\hline Environmental and occupational health & 5 & 4 & 8 & 6 & 13 & 5 \\
\hline Other & 7 & 6 & 6 & 5 & 13 & 5 \\
\hline Maternal and child health & 5 & 4 & 6 & 5 & 11 & 4 \\
\hline Total & 121 & 100 & 130 & 100 & 251 & 100 \\
\hline
\end{tabular}

In addition, 9 round table discussions were convened and leading experts from around the world led the discussions. The primary objective of these discussions was to familiarize participants with the emerging health issues at the regional and global levels. Titles of these round tables were public health in mass gatherings, reaching IHR (2005) compliance, noncommunicable diseases, health systems' strengthening, civil registration and vital statistics, biosafety and waste management in the Eastern Mediterranean region, the burden of noncommunicable diseases among Jordanian youth and rotavirus gastroenteritis burden and prevention.

In recognition and promotion of excellence in applied scientific research, the hosts and organizers awarded the best oral presentation award to Dr R. Alethea de Guzman from the Philippines, who presented a study entitled: A case-controlstudy on a cholera outbreak in Nabua, southern Luzon, Philippines, 2012. The best poster presentation was awarded to Dr Ee Laine TAY from Australia with a poster entitled: Composite surveillance variables are useful for establishing thresholds for influenza surveillance in Victoria, Australia.
For the first time, all sessions of the Conference, including the preconference workshops and roundtable discussions, were recorded and virtually broadcasted to reach a wider audience and allow interested individuals, who were not able to attend the conference in person, to join the Conference online. The Virtual registration logbook showed that 187 people from 57 country participated in online sessions of this conference and its related pre-conference workshops.

The Conference was officially closed on Thursday 15 November 2012 with the presence of leaders in public health from around the globe. Among them was Dr William $\mathrm{H}$. Foege, former CDC Director, Emeritus Presidential Distinguished Professor of International Health, Emory University, Senior Fellow, Bill and Melinda Gates Foundation and winner of (at least) 22 prestigious international awards on public and global health; Dr Mark Rosenberg, President and Chief Executive Officer, the Task Force for Global Health; Dr Larry Brilliant, President of the SKOLL Global Threats Fund; and Dr Jim Yong Kim, President of the World Bank.

\section{Conclusions}

The Conference succeeded in creating opportunities for dialogue among residents and graduates of different FETPs and public health scholars, workers and officials both in the Eastern Mediterranean region and around the globe. The presentations, work-shops and discussions illustrated the urgent need for countries to tackle the communicable and noncommunicable diseases they face in order to reduce morbidity and mortality. While numerous categories of diseases were addressed in the presentations, food- and waterborne diseases were prominent in the countries that had delegates attending the Conference. Furthermore, the Conference revealed that many of the less developed countries are facing double burden of communicable and noncommunicable diseases. Finally in regard to public health networking, the Conference provided the Eastern Mediterranean region with a unique opportunity to demonstrate its ability to contribute to global health issues and its progress and innovation in field epidemiology in the region.

The next EMPHNET regional conference is planned for 2013 in Morocco. 


\section{References}

1. TEPHINET. Introductory page. Training Programs in Epidemiology and Public Health Interventions Network. [Website] (http:// www.tephinet.org/, accessed 15 Janury 2013).

2. Al Nsour M et al. Highlights and conclusions from the Eastern Mediterranean Public Health Network (EMPHNET) conference 2011. Eastern Mediterranean Health Journal, 2012, 18(2):189-191.

3. Al Nsour M, Kaiser R. Networking for applied field epidemiology - Eastern Mediterranean Public Health Network (EMPH-
NET) Conference 2011. Eastern Mediterranean Health Journal, 2011, 17(12):990-993.

4. Field Epidemiology Training Program Standard Core Curriculum. Atlanta, GA, Centers for Disease Control and Prevention, 2006 (http://www.cdc.gov/globalhealth/fetp/pdf/FETP_standard_core_curriculum_508.pdf, accessed 15 January 2013).

5. International health regulations (2005), 2nd ed. Geneva, World Health Organization, 2008 (http://www.who.int/ihr/en/, accessed 15 January 2013). 